\title{
Contaminantes ambientais e os interferentes endócrinos
}

\author{
Environmental contaminants and endocrine disruptors
}

Eveline Gadelha Pereira Fontenele', Manoel Ricardo Alves Martins', Ana Rosa Pinto Quidute', Renan Magalhães Montenegro Júnior'

${ }^{1}$ Serviço de Endocrinologia e Diabetes, Hospital Universitário Walter Cantídio, Universidade Federal do Ceará (UFE), Fortaleza, CE, Brasil
Correspondência para: Eveline Gadelha Pereira Fontenele Rua Capitão Francisco Pedro, 1.290 60430-370 - Fortaleza, CE eveline@huwc.ufc.br

Recebido em 5/Jul/2009 Aceito em 22/Nov/2009

\section{SUMÁRIO}

A toxicidade de diversos poluentes ambientais em seres humanos e demais espécies tem sido habitualmente investigada quanto aos seus efeitos teratogênicos e cancerígenos. Nas últimas décadas, muitos contaminantes têm demonstrado efeitos adversos sobre o sistema endócrino. Atualmente, cerca de onze milhões de substâncias químicas são conhecidas em todo mundo, sendo três mil delas produzidas em larga escala. Numerosos compostos químicos de uso doméstico, industrial e agrícola possuem comprovada atividade hormonal. Entre os produtos químicos com atividade estrogênica, destacam-se hormônios presentes em cosméticos, anabolizantes utilizados em rações animais, fitoestrógenos e poluentes orgânicos persistentes (POPs). Esses agentes que estão presentes nos efluentes industriais, residenciais e das estações de tratamento de água e esgoto representam uma importante fonte de contaminação ambiental. O Programa Internacional de Segurança Química (International Programme on Chemical Safety - IPCS) define como interferente endócrino substâncias ou misturas presentes no ambiente capazes de interferir nas funções do sistema endócrino, causando efeitos adversos em um organismo intacto ou na sua prole. No presente artigo, os autores apresentam uma revisão da literatura atual sobre o papel desses elementos nas doenças endócrinas e metabólicas, os prováveis mecanismos de ação envolvidos, discutindo-se perspectivas futuras em termos de investigação e estratégias para prevenção e redução dos seus possíveis danos. Arq Bras Endocrinol Metab. 2010;54(1):6-16

\section{Descritores}

Interferente endócrino; doenças endócrinas; mecanismo de ação; contaminantes ambientais; revisão

\section{SUMMARY}

The toxicity of various pollutants has been routinely investigated according to their teratogenic and carcinogenic effects. In the last few decades, however, many of such pollutants have been shown to adversely affect the endocrine system of human beings and other species. Currently, more than eleven million chemical substances are known in the world, and approximately 3,000 are produced on a large scale. Numerous chemical composites of domestic, industrial and agricultural use have been shown to influence hormonal activity. Examples of such chemical products with estrogenic activity are substances used in cosmetics, anabolizing substances for animal feeding, phytoestrogens and persistent organic pollutants (POPs). These agents are seen in residential, industrial and urban sewerage system effluents and represent an important source of environmental contamination. The International Programme on Chemical Safety (IPCS) defines as endocrine disruptors substances or mixtures seen in the environment capable of interfering with endocrine system functions resulting in adverse effects in an intact organism or its offspring. In this article the authors present a current literature review about the role of these pollutants in endocrine and metabolic diseases, probable mechanisms of action, and suggest paths of investigation and possible strategies for prevention and reduction of its possible damages. Arq Bras Endocrinol Metab. 2010;54(1):6-16

Keywords

Ambient pollutants; endocrine disruptor; endocrine disease; mechanism of action; review 


\section{INTRODUÇÃO}

A toxicidade de diversos poluentes ambientais tem sido habitualmente investigada quanto a sua teratogenicidade e carcinogenicidade em seres humanos $\mathrm{e}$ demais espécies. Nas últimas décadas, entretanto, o interesse de pesquisadores vem sendo despertado para os efeitos adversos sobre o sistema endócrino observados em alguns ecossistemas e animais de laboratório expostos a químicos ambientais $(1,2,3)$.

Cerca de onze milhões de substâncias químicas são conhecidas em todo o mundo, sendo três mil produzidas em larga escala. Nos Estados Unidos, 1.200 a 1.500 novos registros são feitos a cada ano. Entre elas, numerosos compostos químicos de uso doméstico, industrial e agrícola possuem comprovada atividade hormonal. São inseticidas, detergentes, repelentes, desinfetantes, fragrâncias, solventes, retardantes de chama, entre outros produtos, que estão presentes nos efluentes industriais, residenciais e de estações de tratamento de água e esgoto. Como somente 40 a 50 substâncias químicas são contempladas pelos padrões de potabilidade da água na maioria dos países incluindo o Brasil, sua presença na água, no solo e no ar representa uma importante fonte de contaminação da cadeia alimentar não avaliada pelos órgãos de controle de qualidade (4). A quantidade de publicações indexadas na base de dados PubMed sobre esse assunto aumentou exponencialmente nos últimos três anos, como ilustra a figura 1 .

O objetivo deste artigo é apresentar uma revisão da literatura sobre o papel atual desses elementos nas doenças endócrinas e metabólicas, os prováveis mecanismos de ação envolvidos e as perspectivas futuras em termos de investigação e estratégias para prevenção e redução dos possíveis danos.

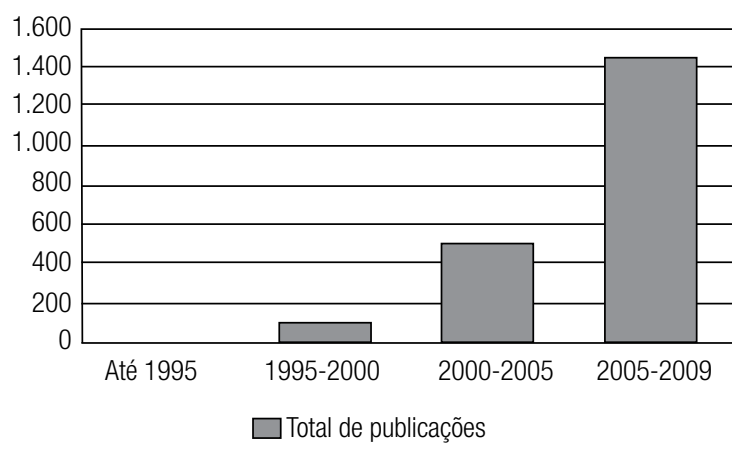

Figura 1. Número de publicações indexadas com o termo "endocrine disruptor" pelo PubMed. Fonte: http://www.ncbi.nlm.nih.gov/pubmed

\section{MECANISMOS DE AÇÃO HORMONAL}

De modo geral, os hormônios se ligam a receptores específicos exercendo um efeito regulador nos tecidos-alvo. Por suas similaridades estruturais, eles podem ser agrupados em cinco classes principais: 1) derivados de aminoácidos: dopamina, catecolaminas e hormônios tireoidianos; 2) neuropeptídios: GnRH, GHRH, TRH, somatostatina (SMS), vasopressina; 3) proteicos: insulina, LH, FSH, TSH, hCG, PTH, ACTH, peptídeos fatores de crescimento; 4) esteroides: cortisol, aldosterona, estrógeno, progesterona e andrógenos sintetizados a partir do colesterol; 5) derivados de vitaminas: retinoides e vitamina $\mathrm{D}$. Como regra, hormônios proteicos, peptídeos e derivados de aminoácidos interagem com receptores de membrana. Esteroides, hormônios tireoidianos, vitamina D e retinoides são lipossolúveis e interagem com receptores nucleares intracelulares (5).

Existem quatro tipos de receptores de membrana e dois tipos de receptores nucleares (Tabela 1). O receptor nuclear tipo 1 se liga aos esteroides (estrógeno, andrógeno, progesterona, glico e mineralocorticoide) e o tipo 2 se liga aos hormônios tireoidianos, vitamina $\mathrm{D}$, ácido retinoico, ácidos graxos livres e eicosanoides (5).

Os domínios de ligação ao DNA dos receptores nucleares são compostos por dois dedos de zinco contendo sequências específicas de reconhecimento dos genes-alvo. A maioria dos receptores nucleares se liga ao DNA como dímeros e sendo assim cada monômero reconhece um padrão ou sequência de DNA. Os receptores tipo 1 ligam-se ao DNA como homodímeros e os

Tabela 1. Receptores endócrinos e seus respectivos ligantes (5)

\begin{tabular}{|c|c|c|}
\hline Grupo & Tipo & Ligante natural \\
\hline \multirow[t]{4}{*}{ Membrana } & $\begin{array}{l}\text { Transmembrana ligada à } \\
\text { proteína G }\end{array}$ & $\begin{array}{l}\text { Adrenalina, LH, FSH, TSH, } \\
\text { glucagon, PTH, PTHrP, ACTH, } \\
\text { MSH, GHRH, CRH, SMS, TRH, } \\
\text { GnRH }\end{array}$ \\
\hline & Tirosina quinase & $\begin{array}{l}\text { Insulina, fator de crescimento } \\
\text { epidérmico (EGF), IGF-I e fator de } \\
\text { crescimento neural (NGF) }\end{array}$ \\
\hline & Citocina quinase & GH e PRL \\
\hline & Serina quinase & Activina e TGF- $\beta$ \\
\hline \multirow[t]{2}{*}{ Nuclear } & 1 & $\begin{array}{l}\text { Glicocorticoide (GR), } \\
\text { mineralocorticoide (MR), } \\
\text { estrógeno (ER), progesterona (PR) }\end{array}$ \\
\hline & 2 & $\begin{array}{l}\text { Hormônios tireoidianos (TR), } \\
\text { vitamina D (VDR), ácido retinoico } \\
\text { (RXR), ácidos graxos livres e } \\
\text { eicosanoides (PPAR) }\end{array}$ \\
\hline
\end{tabular}


receptores tipo 2 , como heterodímeros em combinação com receptores retinoides X (RXRs). A especificidade do receptor para a sequência de DNA é determinada pela sequência do seu sítio de ligação ("half-site”), pela sua orientação (tipo 1 - palindrômica, tipo 2 - repetições diretas) e pelo espaçamento entre seus sítios de ligação (5). Os receptores de estrógeno (ER) particularmente são pouco específicos e essa característica os torna suscetíveis à ativação por uma variedade de compostos ambientais (xenoestrógenos) que muitas vezes exibem pouca semelhança com o ligante de alta afinidade, estradiol (Figura 2). Fitoestrógenos, agentes anabolizantes utilizados em rações animais, substâncias presentes em cosméticos, produtos químicos e poluentes orgânicos persistentes (POPs) são alguns exemplos de xenoestrógenos (6).<smiles>CC12CCC3c4ccc(O)cc4CCC3C1CC[C@@H]2O</smiles><smiles>CC12CCC3c4ccc(O)cc4CCC3C1CCC2=O</smiles><smiles>CC12CCC3C4CCC(=O)CC4CCC3C1CC[C@@H]2O</smiles><smiles>CC/C(=C(\CC)c1ccc(O)cc1)c1ccc(O)cc1</smiles><smiles>CC/C(=C(\c1ccccc1)c1ccc(OCCN(C)C)cc1)c1ccccc1</smiles><smiles>Clc1ccc(C(c2ccc(Cl)cc2)c2ccc(Cl)cc2)cc1</smiles><smiles>Cc1ccc([C@H](Cl)c2ccc(Cl)cc2)cc1</smiles>

$o, \not p-\mathrm{DDT}$<smiles>O=C1C2CC3C(C1C2(Cl)Cl)C(Cl)(Cl)C3(Cl)Cl</smiles><smiles>CC(C)(C)CC(C)(C)c1ccc(O)cc1</smiles><smiles>COc1ccc(C(c2ccc(O)cc2)c2ccc(OC)cc2)cc1</smiles>

Methoxychlor<smiles></smiles><smiles>Cc1ccc(O)cc1</smiles><smiles>Oc1ccc(C(c2ccc(O)cc2)c2ccc(O)cc2)cc1</smiles>

Hydroxyphenyltrichloroethane<smiles>CC(c1ccccc1)(c1ccc(O)cc1)c1ccc(O)cc1</smiles><smiles>CCCCOC(=O)c1ccccc1C(=O)OCc1ccccc1</smiles>

Figura 2. Estruturas químicas de alguns compostos naturais e sintéticos capazes de interagir com receptor de estrógeno (6). 


\section{INTERFERENTES ENDÓCRINOS E SEUS MECANISMOS DE AÇÃO}

Embora alguns pesquisadores já demonstrassem efeitos endócrinos de agentes químicos no passado, o termo interferente endócrino, do inglês "endocrine disruptor", começou a ser empregado, em 1991 pela zoóloga Theo Colburn, para denominar agentes ou substâncias químicas presentes no meio ambiente, capazes de se acumular no solo e nos sedimentos dos rios, contaminarem a cadeia alimentar, se ligar a receptores endócrinos e promover alterações na síntese, secreção, metabolismo e/ou ação hormonais (3). Atualmente, o Programa Internacional de Segurança Química (International Programme on Chemical Safety, IPCS) define como interferente endócrino (IE) substâncias ou misturas presentes no ambiente capazes de interferir no sistema endócrino, causando efeitos adversos em um organismo intacto ou sua prole $(7,8)$

Os IEs em geral possuem múltiplos sítios e mecanismos de ação, desde a ligação do hormônio endógeno ao seu receptor, como as etapas de síntese, transporte e metabolismo do ligante natural. Embora em potência menor, eles frequentemente agem como agonistas ou antagonistas. A relação dose-resposta, no entanto, é ainda um tema controverso, pois seus efeitos em baixas doses ainda são discutíveis e fatores como frequência e duração da exposição, além da etapa do desenvolvimento em que ela ocorre, devem ser considerados. Caracteristicamente, os sintomas da exposição ocupacional em adultos são revertidos com sua interrupção, sendo seus efeitos indetectáveis ou compensados por mecanismos hormonais. Contudo, quando ocorre durante a gestação ou nos primeiros anos de vida, pode trazer danos irreversíveis (7).

Por via cutânea, nasal ou oral, os IEs são absorvidos e passam a interferir no equilíbrio do sistema endócrino, rompendo a sequência natural dos mecanismos de autorregulação. Essa interferência depende de diversos fatores. Tomando como exemplo o xenoestrógeno, sua ação estrogênica ou antiestrogênica dependerá da concentração do ligante natural e do órgão-alvo específico, pois a distribuição dos diferentes tipos de receptores (ER- $\alpha$ e ER- $\beta$ ) varia conforme o tecido. Os ER- $\alpha$ são encontrados principalmente nas mamas e no útero e os ER- $\beta$, no osso e no sistema cardiovascular. O estradiol tem elevada afinidade por ambos, enquanto fitoesteroides como as isoflavonas são mais seletivos para ER- $\beta$ $(9,10)$. Entre os xenoestrógenos, destaca-se o papel dos POPs, compostos lipofílicos de elevada toxicidade que são muito resistentes à degradação. Em razão de sua estabilidade, acabam se perpetuando na cadeia alimentar, sendo transportados a grandes distâncias a partir do seu sítio original até mesmo para regiões onde nunca foram usados. Além de interferentes endócrinos, eles são carcinogênicos e possuem ações deletérias no sistema nervoso e imune (8).

Em 2001, uma convenção realizada em Estocolmo elaborou um tratado visando eliminar, em nível mundial, a produção e o uso dos doze principais POPs (11). São pesticidas, insumos utilizados na indústria química ou resíduos de processos industriais, cujos efeitos conhecidos até o momento sobre a saúde dos animais e do homem estão listados na tabela 2. Selecionaram-se um pesticida (DDT) e alguns compostos de uso industrial (PCB, bisfenol, ftalato e organotinas) para uma apresentação mais detalhada dos mecanismos de ação e seus efeitos endócrinos.

Tabela 2. Os doze poluentes orgânicos persistentes (POPs) eleitos pela convenção de Estocolmo e seus efeitos principais. Adaptado de Quental \& Moraes (66)

\begin{tabular}{|c|c|}
\hline Substância & Efeitos conhecidos ou possivelmente relacionados \\
\hline DDT & $\begin{array}{l}\text { IE } \\
\text { Cancerígeno (mama) } \\
\text { Alterações no SNC }\end{array}$ \\
\hline $\begin{array}{l}\text { Aldrina, dieldrina e } \\
\text { endrina }\end{array}$ & $\begin{array}{l}\text { Supressão do sistema imunológico } \\
\text { Convulsões (exposição aguda) e dano hepático (exposição crônica) } \\
\text { Efeitos sobre o comportamento } \\
\text { IE }\end{array}$ \\
\hline $\begin{array}{l}\text { Clordano e } \\
\text { heptacloro }\end{array}$ & $\begin{array}{l}\text { Cancerígeno potencial (mama) } \\
\text { Danos ao SNC e ao fígado (animais) }\end{array}$ \\
\hline $\begin{array}{l}\text { Hexaclorobenzeno } \\
\text { (HCB) }\end{array}$ & $\begin{array}{l}\text { Cancerígeno potencial (em roedores) } \\
\text { Efeitos sobre o DNA de hepatócitos humanos } \\
\text { Alteração na função leucocitária (exposição ocupacional) } \\
\text { IE } \\
\text { Baixas doses levam à alteração na produção de esteroides } \\
\text { pelas células adrenocorticais (em ratos) } \\
\text { Porfiria cutânea tardia (exposição aguda) } \\
\text { Bócio }\end{array}$ \\
\hline Mirex & $\begin{array}{l}\text { Carcinogênico (em ratos) } \\
\text { Associado à supressão do sistema imunológico } \\
\text { Catarata nos fetos } \\
\text { Hipertrofia do fígado após exposição prolongada a doses } \\
\text { reduzidas }\end{array}$ \\
\hline Toxafeno & $\begin{array}{l}\text { Cancerígeno } \\
\text { IE } \\
\text { Distúrbio no desenvolvimento (mamíferos) }\end{array}$ \\
\hline Dioxinas e furanos & $\begin{array}{l}\text { IE } \\
\text { Alteração no sistema imunológico e no desenvolvimento } \\
\text { Cancerígeno (dioxina) }\end{array}$ \\
\hline PCBs & $\begin{array}{l}\text { IE } \\
\text { Alterações neurológicas e comportamentais } \\
\text { Baixos resultados psicomotores em humanos (exposição na } \\
\text { vida fetal) }\end{array}$ \\
\hline
\end{tabular}

DDT: dicloro-difenil-tricloroetano; IE: interferente endócrino; PCBs: bifenilas policlorinadas. Adaptado de Quental e Moraes (66). 


\section{Dicloro-difenil-tricloroetano}

Em 1939, Paul Muller recebeu o prêmio Nobel pela descoberta de um composto organoclorado eficaz como inseticida (12). Por se tratar de uma molécula estável e lipossolúvel, requer cerca de oito anos para que metade da quantidade absorvida seja metabolizada (13). Após a II Guerra Mundial, seu uso aumentou enormemente, tornando aparente diversos problemas. Muitas espécies de insetos desenvolveram resistência ao dicloro-difenil-tricloroetano (DDT) e peixes contaminados mostraram-se sensíveis à sua toxicidade.

Gray e cols. (14) demonstraram que o DDT possui ação estrogênica e seu metabólito, p,p'- DDE, tem ação antiandrogênica in vitro e in vivo. Os primeiros efeitos adversos do DDT descritos foram observados após grandes exposições ocupacionais ou acidentes industriais. Recentemente, De Jager e cols. (15) realizaram um estudo epidemiológico transversal envolvendo 116 homens jovens que habitavam áreas endêmicas de malária em Chiapas (México), onde o DDT havia sido pulverizado até o ano 2000. A concentração plasmática de p,p'-DDE foi utilizada como parâmetro de exposição ao DDT e se mostrou cem vezes maior que $\mathrm{o}$ relatado em populações não expostas. A análise do esperma revelou alteração de vários parâmetros que se correlacionaram positivamente com as concentrações de p,p'-DDE, tais como diminuição do percentual de espermatozoides móveis e de espermatozoides com defeitos morfológicos na cauda, além de defeitos genéticos, indicando efeitos adversos sobre a função testicular e/ou regulação dos hormônios reprodutores. Esse foi o primeiro estudo epidemiológico a demonstrar efeito após exposição não ocupacional ao DDT (15).

$\mathrm{Na}$ Inglaterra, pesquisadores levantaram uma possível relação entre a presença de tumores adrenocorticais (TCA) e a exposição a pesticidas (16). No Brasil, Sandrini e cols. (17) comentam a importância da exposição ao DDT como fator contribuinte para a alta incidência de TCA em crianças no Paraná. Figueiredo e cols. descreveram nessa mesma população a presença da mutação germinativa R337H no gene supressor tumoral TP53, fato este não observado em portadores de TCA provenientes de outras regiões do país. Os autores sugerem um papel desse pesticida na sua origem (18).

A Convenção de Estocolmo e o governo brasileiro restringem a produção e o uso do DDT aos programas de combate aos vetores de doenças transmitidas por artrópodes, como a malária. Apesar dessas ações, devido à sua persistência ambiental o DDT continua e continuará por muitos anos a contaminar os seres humanos (19).

\section{Bifenilas policlorinadas}

As bifenilas policlorinadas (PCBs) são hidrocarbonos aromáticos clorinados sintéticos que foram produzidos e comercializados nos Estados Unidos de 1929 a 1977. Em decorrência de sua propriedade não inflamável, estabilidade química, elevado ponto de ebulição e isolamento elétrico, foram utilizados em centenas de aplicações industriais e comerciais, como plastificantes em tintas, plásticos e produtos de borracha; em pigmentos, papéis e muitas outras aplicações, incluindo equipamentos refrigeradores e capacitores elétricos. Caracteristicamente sua persistência no meio ambiente é estimada em torno de 40 anos e eles são capazes de se acumular na cadeia alimentar. Com a preocupação acerca dos riscos potenciais à saúde do homem, sua produção e distribuição foram encerradas nos Estados Unidos em 1977 e no Brasil em 1981. Entretanto, equipamentos fabricados antes da proibição poderiam continuar com o produto, o que representa um risco ocupacional potencial para pessoas que fazem reparos em equipamentos elétricos ainda hoje $(20,21)$.

Diversas ações das PCBs sobre o sistema endócrino vêm sendo relatadas: redução dos níveis de hormônios tireoidianos em humanos e animais $(22,23)$, interferência na síntese de esteroides gonadais e adrenais (24-27), prejudicando assim o crescimento e o desenvolvimento.

O composto PCB-126 liga-se ao receptor aril hidrocarbono (AhR) translocando-se do citoplasma para o núcleo e interagindo com elementos específicos do DNA denominados elementos dioxina-responsivos (DRES). Por fim, ele ativa a expressão transcripcional de uma bateria de genes-alvo, incluindo as enzimas do citocromo P450 CYPlAl e CYPlBl (28).

Estudos demonstram que o PCB-126 reduz a síntese de andrógeno, de modo dose-dependente, nas células $\mathrm{H} 295 \mathrm{R}$ adrenocorticais e gonadais humanas e, em altas concentrações, estimulam a síntese de cortisol e aldosterona por ativação de enzimas do citrocomo P450 CYP11B1 e CYP11B2 que catalisam as etapas finais das vias de síntese desses esteroides $(29,30)$.

Lin e cols. (31), investigando o mecanismo molecular por meio do qual o PCB-126 induziria alterações na esteroidogênese, demonstraram que essa substância regula a expressão de CYPl1Bl e CYPl1B2 por uma via póstranscripcional AhR-independente (31). A despeito da ausência de prova direta, essas alterações nos níveis de hor- 
mônios esteroides, particularmente os níveis de cortisol e aldosterona, podem estar associadas com a alta incidência de diabetes melito e mortalidade cardiovascular observada em pessoas altamente expostas às $\mathrm{PCBs}(32-35)$. O conhecimento dos mecanismos pelos quais o PCB-126 interfere na esteroidogênese poderá ajudar a reduzir os riscos.

\section{Bisfenol-A}

O bisfenol-A (BPA) é um dos produtos químicos de maior prevalência nos produtos comercializados na atualidade. Somente em 2003 cerca de dois milhões de toneladas do produto foram produzidos e o aumento anual na sua demanda é de $6 \%$ a $10 \%$. Está presente em selantes dentários, cremes, resinas epóxi, tubulações de ar-condicionado, mamadeiras e garrafas plásticas (policarbonato). Como o BPA pode migrar do policarbonato quando exposto a elevadas temperaturas, alimentos acondicionados em recipientes plásticos podem ser contaminados pelo bisfenol (36).

Diversos efeitos biológicos do BPA em uma variedade de tecidos têm sido atribuídos à exposição ambiental em baixas doses. Estudos utilizando modelos in vitro têm demonstrado uma variedade de vias moleculares por meio das quais o BPA pode desencadear uma resposta celular. Como um estrógeno não esteroide, ele interfere com a ligação de $17 \beta$-estradiol ao seu receptor nos tecidos-alvo. Contudo, as atividades interferentes endócrinas primárias do BPA estendem-se além da sua capacidade de mimetizar, amplificar ou inibir a atividade de estrógenos endógenos e/ou de interferir na ação do receptor nuclear de estrógeno e incluem: efeitos androgênicos, no metabolismo, na função tireoidiana, na diferenciação e função do sistema nervoso central, no desenvolvimento e no sistema imune (37).

Ações farmacocinéticas e metabólicas secundárias ao BPA que causam impacto na biodisponibilidade de hormônios esteroides também têm sido descritas e incluem modificações na expressão e atividade da enzima citocromo P450, alterações na expressão e/ou interações com a proteína ligadora do hormônio. Portanto, o BPA é claramente um composto interferente endócrino (IE) no amplo sentido da palavra. Por seus mecanismos pleiotrópicos de ação, defini-lo meramente com um modulador seletivo do receptor de estrógeno (SERM), tal como raloxifeno ou tamoxifeno, ou exclusivamente como um xenoestrógeno seria uma definição incompleta, pois descreve apenas parcialmente a extensão das atividades interferentes endócrinas e outras atividades biológicas do BPA (38).
Calafat e cols. (39) detectaram a presença de bisfenol e nonifenol em 95\% e $51 \%$ das 371 amostras de urina de adultos americanos, respectivamente. Em outro estudo, cujo objetivo foi associar a exposição ao BPA com o aumento na incidência de doença cardiovascular, AVC, diabetes, artrite, asma, DPOC, câncer, hepatopatia e tireoidopatia, Lang e cols. (40) avaliaram amostras de urina de 1.455 indivíduos entre 18 e 74 anos de idade. A concentração urinária de BPA se associou positivamente com uma maior prevalência de doença cardiovascular (DCV), diabetes e anormalidades em enzimas hepáticas mesmo após ajuste para fumo, índice de massa corporal (IMC), condição socioeconômica, educação, idade, sexo, etnia, circunferência abdominal e creatinina urinária. A reprodução desses dados em estudos longitudinais é necessária para confirmar esses achados e proporcionar evidência de relação causa-efeito.

A adiponectina é um hormônio específico do tecido adiposo subcutâneo que apresenta propriedade antiinflamatória e sensibilizadora de insulina, conferindo, portanto, proteção contra a síndrome metabólica. (41). Recentemente, Hugo e cols. (42) compararam os efeitos de BPA, estradiol (E2) e um antagonista dos dois subtipos de receptores estrogênicos (ER- $\alpha$ e ER- $\beta$ ) sobre a secreção de adiponectina por tecido adiposo humano visceral, subcutâneo, mamário e por adipócitos maduros em meio de cultura. Utilizando material obtido de cirurgias plásticas (mamoplastia, abdominoplastia) ou gastroplastia redutora ("bypass" gástrico), os autores observaram que BPA (em concentrações de 0,1 a $\mathrm{lnM}$ ) suprimiu a liberação de adiponectina em todas as amostras analisadas, sendo tão ou mais eficiente que E2 em concentrações equimolares, mas o mecanismo dessa ação necessita ser esclarecido. Dado sua persistência no meio ambiente, presença no soro humano e capacidade de suprimir a liberação de adiponectina em concentrações nanomolares, o BPA pode realmente ser o principal IE que afeta adversamente a homeostase metabólica e suas manifestações.

\section{Organotinas}

As organotinas representam uma classe de POPs com potentes propriedades interferentes sobre o sistema endócrino tanto em invertebrados como em vertebrados. O composto cloreto de tributilina (TBT) é uma organotina que tem sido utilizada como fungicida em tintas impermeabilizantes para embarcações. O TBT apresenta propriedade agonista do receptor X de retinoide $(\operatorname{RXR} \alpha, \operatorname{RXR} \beta$ e $\operatorname{RXR} \gamma)$ e do receptor ativado 
pelo proliferador do peroxissomo (PPAR $\gamma$ ). PPARs têm um papel essencial na regulação da diferenciação celular, metabolismo de carboidratos, lipídeos e proteínas e na tumorigênese. Em tese, as organotinas ativariam inapropriadamente esses receptores, estimulariam a diferenciação do adipócito, contribuindo para uma predisposição e/ou maior suscetibilidade a obesidade e desordens metabólicas correlatas nos indivíduos expostos, atuando, assim, como obesógenos ambientais. A ligação entre exposição a organotinas e diferenciação de adipócitos e obesidade abre uma importante e nova área de pesquisa sobre as potenciais influências ambientais nas doenças que afligem a humanidade (43).

\section{Ftalatos}

Os ftalatos são um grupo de compostos químicos derivados do ácido ftálico, utilizado como aditivo para deixar o plástico mais maleável. Estão presentes em produtos de higiene pessoal, cosméticos, tintas, tubos de PVC, embalagens de alimentos, adesivos, plásticos, brinquedos e borrachas escolares e têm sido incriminados como interferentes da função reprodutora masculina (44). Estudos observacionais sugerem que esse grupo químico apresenta ação antiaandrogênica em humanos. Swan e cols. (45) demonstraram uma correlação inversa entre a concentração de ftalato na urina materna e a distância urogenital em fetos masculinos. Da mesma forma, Main e cols. (46) demonstraram uma associação inversa dose-dependente entre ftalatos no leite materno e níveis de testosterona em meninos aos 3 meses de idade.

Para avaliar os efeitos do ftalato em tecidos humanos, Lambrot e cols. (47) utilizaram testículos obtidos de aborto de fetos aparentemente normais, realizado legalmente durante o primeiro trimestre de gestação (7-12 semanas). Eles foram cultivados durante três dias com ou sem mono-2-etilhexyl-phthalate (MEHP) em condições basais e após estímulo do LH. Não foram evidenciados efeitos inibitórios sobre a síntese de testosterona, apoptose ou proliferação das células de Sertoli. Os autores observaram que na concentração de $10^{-4} \mathrm{M}$ do ftalato houve redução na expressão de RNAm de hormônio anti-mülleriano $(\mathrm{AMH})$ e do número de células germinativas por aumento de sua apoptose. Eles comentam que o estudo em questão analisou somente o efeito do MEHP especificamente sobre o testículo, não sendo possível descartar que os efeitos relatados em estudos observacionais fossem atribuídos à ação direta sobre o trato reprodutivo. Essa é a primeira demonstra- ção experimental que ftalatos alteram o desenvolvimento de linhagem de células germinativas e apresentam efeito deletério potencial sobre a fertilidade masculina na vida adulta (47).

\section{NOSSO FUTURO ROUBADO?}

Os sistemas reprodutor, nervoso e imunológico são os principais alvos dos interferentes endócrinos. Efeitos no sistema reprodutor são descritos em diversas espécies.

Exposição aos pesticidas levou a um declínio populacional de focas bálticas por seu impacto negativo na função reprodutora e imunológica $(48,49)$. Anormalidades no sistema reprodutor, feminilização de peixes, masculinização e declínio populacional de algumas espécies de invertebrados, afinamento da casca do ovo, alterações no desenvolvimento gonadal e declínio populacional de aves de rapina foram observados e relacionados com exposição aos IEs (50-52). Em jacarés, a exposição ao pesticida difocol, um xenoestrógeno, resultou no desenvolvimento de anormalidades reprodutivas e aumento da mortalidade (53). Todas essas observações foram relatadas em áreas de grande contaminação.

Em seres humanos, exposição aos IEs tem sido associada a oligospermia, alterações na esteroidogênese, criptorquidismo, hipospadia, endometriose, puberdade precoce, aborto, infertilidade, distúrbios de comportamento e doenças autoimunes (54-58). Exposição aos xenoestrógenos na vida intrauterina, durante a infância ou adolescência, tem sido relacionada com o aumento dos casos de câncer de mama, puberdade precoce ou acelerada (59).

Do mesmo modo, o aumento na prevalência da obesidade, que se tornou uma preocupação mundial nos últimos vinte anos, vem sendo recentemente relacionado à exposição aos IEs. Newbold e cols. (60) descrevem como potenciais alvos dos interferentes a diferenciação do adipócito e os mecanismos que envolvem a homeostase do peso corporal (60). No Brasil, as maiores prevalências de obesidade são encontradas nas regiões mais industrializadas do país. Em um estudo realizado em Santa Catarina, encontrou-se uma prevalência de obesidade de $23,5 \%$, mais que o triplo da média mundial de $7 \%$ (61).

Diante dos efeitos danosos da contaminação ambiental, estariam ameaçadas nossa fertilidade, inteligência e sobrevivência? (62). Apesar de os estudos atuais sugerirem possíveis danos à saúde do homem, eles ain- 
da falham em demonstrar associação causal entre baixo nível de exposição à IE e doenças. A situação da relação causa-efeito no cenário da evidência científica é que vai determinar o tipo de ação a ser adotada (Tabela 3). Uma avaliação estruturada e qualitativa dos riscos à saúde humana atribuíveis aos interferentes endócrinos, com base nos dados disponíveis até o momento, é apresentada na tabela 4 (63). Como se pode ver, as informações acerca do papel dos químicos ambientais no desenvolvimento de doenças em humanos fornecem um conhecimento ainda básico, permanecendo limitada à nossa capacidade de mensurar o risco da exposição e prevenir tais consequências em nossa espécie, diante do contexto de incerteza científica. Para reduzir essa limitação, é imprescindível que instrumentos sensíveis e bem validados capazes de avaliar a exposição aos IEs e seus possíveis impactos a curto e longo prazo na saúde humana sejam desenvolvidos.

Tabela 3. Situação da relação causa-efeito baseada em evidência científica e o tipo de ação a ser adotada

\begin{tabular}{lll}
\hline Situação & Estado do conhecimento & Exemplos de ação \\
\hline Risco (R) & $\begin{array}{l}\text { Impactos e probabilidades } \\
\text { conhecidas }\end{array}$ & Prevenção \\
Incerteza (U) & $\begin{array}{l}\text { Impactos conhecidos e } \\
\text { probabilidades desconhecidas }\end{array}$ & Cautela \\
Ignorância (I) & $\begin{array}{l}\text { Impactos e probabilidades } \\
\text { desconhecidas }\end{array}$ & Precaução \\
\hline
\end{tabular}

Adaptado de Martin e cols. (63).

\section{QUE PODEMOS FAZER?}

As duas principais linhas de ação para redução do impacto dos IE incluem a pesquisa científica e as ações individuais e coletivas.

Em relação à pesquisa científica, mais estudos precisam ser elaborados visando esclarecer o papel dos contaminantes ambientais sobre os diversos distúrbios endócrinos e metabólicos, certos tipos de câncer, entre outras enfermidades. A detecção dos contaminantes mais frequentemente em contato com seres humanos (64-65), os mecanismos de ação, a reversibilidade dos efeitos e a relação causal entre exposição em baixa dose e doenças são tópicos essenciais a serem mais explorados, sejam a partir de estudos em animais ou por estudos epidemiológicos observacionais e longitudinais em humanos. Enquanto isso, várias medidas podem ser tomadas em diferentes esferas de atuação.

$\mathrm{Na}$ esfera individual, uma maior racionalidade no consumo de produtos industrializados, reduzindo, re- ciclando e reutilizando materiais cuja decomposição no meio ambiente é lenta e fonte de liberação dos tais poluentes (66). Na esfera da coletividade, como família, escola, condomínios, associações de moradores, a soma dessas ações individuais torna mais perceptíveis os seus efeitos. Uma sociedade mais consciente pode pressionar por políticas públicas, em que agências reguladoras, organizações não governamentais, associações e ministérios possam trabalhar juntos e efetivamente em questões como o saneamento, coleta seletiva, estações de tratamento de água e esgoto, controle de aterros sanitários e usinas de reciclagem de lixo. Além disso, os órgãos responsáveis pela liberação da utilização de novos agentes químicos e produtos industrializados devem procurar verificar não apenas os efeitos cancerígenos e teratogênicos, mas também a interferência no sistema endócrino-metabólico.

Algumas dessas medidas já podem ser observadas em muitos países. Na Califórnia, em março de 2007, foi movido um processo contra fabricantes e varejistas de mamadeiras plásticas por não advertir que esses produtos contêm BPA e podem oferecer um risco potencial à saúde e ao desenvolvimento de bebês e crianças. Em abril de 2008, na cidade de Ottawa, Canadá, o Ministério do Meio Ambiente proibiu as mamadeiras de policarbonato por declarar oficialmente que o BPA é tóxico. Na mesma época, o senador americano Charles E. Schumer anunciou que pretendia apresentar um projeto de lei visando à proibição total do uso de plásticos relacionados com o BPA em produtos infantis e também em qualquer recipiente para comida ou bebida para adultos.

Jonh Baird e Tony Clement, ministros do meio ambiente e da saúde canadenses, justificaram suas ações ao declararem (67):

"Não vamos esperar os efeitos do bisfenol-A a longo prazo para tomar medidas de proteção ao nosso povo e nosso ambiente." Jonh Baird

"Esse produto químico apresenta um risco elevado, para recém-nascidos e crianças com até 18 meses, de desenvolver sintomas comportamentais e neurológicos numa fase posterior de suas vidas". Tony Clement

\section{CONCLUSÃO}

Após vários anos de intensa negociação entre governos, a Convenção de Estocolmo (CE) foi assinada no ano de 2001 por representantes de mais de 120 países. Ela os obriga, entre outras ações, a desenvolver em dois 
Tabela 4. Avaliação estruturada e qualitativa dos riscos à saúde humana atribuíveis aos interferentes endócrinos

\begin{tabular}{|c|c|c|c|c|}
\hline Efeitos dos IEs & Incidência & Associação & Consequência & Situação \\
\hline \multicolumn{5}{|l|}{ Sistema reprodutor } \\
\hline Qualidade do esperma & + & ++ & $+(?)$ & $\mathrm{U}(\mathrm{l})$ \\
\hline Fecundidade e fertilidade & $-/+$ & + & ++ & U \\
\hline Abortos espontâneos & $?$ & + & + & U \\
\hline Taxa de nascidos M:F & $-/+$ & + & $-/+(?)$ & । \\
\hline Anomalias do trato reprodutor masculino & $-/+$ & + & + & U \\
\hline Prostatite & $?$ & + & ++ & U \\
\hline Endometriose & ++ & ++ & ++ & U \\
\hline Puberdade precoce & + & + & $-/+(?)$ & । \\
\hline Síndrome dos ovários policísticos & $?$ & + & ++ & U \\
\hline Redução da lactação & $?$ & ++ & ++ & U \\
\hline \multicolumn{5}{|l|}{ Neurocomportamental } \\
\hline Desenvolvimento neuropsicomotor & $-/+$ & ++ & $?$ & । \\
\hline Sistema nervoso adulto & $?$ & ++ & ? & । \\
\hline Comportamento dependente do gênero & $?$ & + & $?$ & । \\
\hline \multicolumn{5}{|l|}{ Sistema imunológico } \\
\hline Prejuízo da função imunológica & + & + & ++ & U \\
\hline \multicolumn{5}{|l|}{ Câncer } \\
\hline Mama & ++ & $-/+$ & +++ & U \\
\hline Endométrio & $-1+$ & $-1+$ & ++ & U \\
\hline Testículo & ++ & + & ++ & U \\
\hline Próstata & ++ & ++ & +++ & U \\
\hline Tireoide & + & $-1+$ & + & U \\
\hline
\end{tabular}

?: Ausência de evidência sobre a incidência ou associação; consequência não está claramente definida.

-/+: evidência inconclusiva sobre incidência ou associação; consequência é um biomarcador de saúde populacional.

+: evidência escassa de crescente incidência ou influência ambiental; associação baseada em dados de animais ou estudos in vitro; consequência gera um impacto significante na saúde individual. ++: algumas evidências de tendência crescente da incidência ou influência ambiental; evidência epidemiológica de associação com pelo menos um CDE; ou impacto significante sobre saúde pública ou individual.

+++ : um grande impacto tanto na saúde individual quanto coletiva.

I: ignorância.

$\mathrm{U}$ : incerteza.

Adaptado de Martin e cols. (63).

anos um plano de metas visando parar a instalação ou a ampliação de processos que produzam os principais POPs, e identificar, recolher e destruir estoques indesejados e/ou obsoletos de POPs. Muitas dessas substâncias químicas estão armazenadas há anos em condições inseguras e podem estar contaminando o solo e a água e intoxicando animais e pessoas. No Brasil, a CE foi promulgada em 2005, com força de Lei Internacional.

A Convenção reconhece que será economicamente difícil para alguns países colocarem em prática seus termos e por isso determina que os países ricos ofereçam ajuda financeira e técnica aos países em dificuldade. Já existe apoio a vários projetos sobre POPs em muitos países (11). Portanto, cabe à comunidade científica, por meio de suas sociedades, fornecer informações seguras aos órgãos governamentais e à população em geral. Assim, medidas cabíveis poderão ser empregadas de modo a minimizar os potenciais danos atribuíveis aos interferentes endócrinos sobre o meio ambiente e a saúde do homem.
Agradecimentos: ao professor Horácio Dídimo do Departamento de Literatura (UFC), mestre em Literatura Brasileira (UFPB), doutor em Literatura comparada (UFMG), membro da Academia Cearense de Letras, da Academia Cearense da Língua Portuguesa e correspondente da Academia de Letras e Artes Mater Salvatoris (Salvador-Bahia), por sua gentil colaboração e aconselhamento técnico para a tradução mais adequada do termo "endocrine disruptor".

Declaração: os autores declaram não haver conflitos de interesse científico neste estudo.

\section{REFERÊNCIAS}

1. Colborn T. Pesticides - How research has succeeded and failed to translate science into policy: endocrinological effects on wildlife. Environ Health Perspect. 1995;103 (Suppl 6):81-5.

2. Alves C, Flores LC, Cerqueira TS, Toralles MBP. Exposição ambiental a interferentes endócrinos com atividade estrogênica e sua associação com distúrbios puberais em crianças. Cad Saúde Pública. 2007;23(5):1005-14.

3. Bern HA, Blair P, Brasseur S, Colborn T, Cunha G, Davis W, et al. Statement from the work session on chemically-induced altera- 
tions in sexual development: the wildlife/human connection. In: Colborn T, Clement C. Chemically-induced alterations in sexual and functional development: The Wildlife/Human Connection. eds Princeton Scientific Publishing Co., NJ, U.S. 1992. p. 1-8.

4. Sodré FF, Montagner CC, Locatelli MAF, Jardim WF. Ocorrência de interferentes endócrinos e produtos farmacêuticos em águas superficiais da região de Campinas. J Braz Soc Ecotoxicol. 2007;2:187-96.

5. Jameson JL. Principles of Endocrinology. In: Jameson JL. Harrison's endocrinology 16th ed: New York: McGraw Hill; 2006. p. 1-15.

6. Bolger R, Wiese TE, Ervin K, Nestich S, Checovich W. Rapid screening of environmental chemicals for estrogen receptor binding capacity. Environ Health Perspect. 1998;106(9):551-7.

7. DamstraT, Barlow S, Bergman A, Kavlock R, Van Der Kraak G. Global assessment of the state-of-the-science of endocrine disruptors Chapter 1. [database on the internet] on behalf of the World Health Organization, the International Labour Organization and the United Nations Environment Programme. International Programme on Chemical Safety. Geneva. Switzerland. Disponível em: http://www.who.int/ipcs/publications//ch1.pdf. Acesso em: 7 de setembro de 2008.

8. Thundiyil JG, Solomon GM, Miller MD. Transgenerational exposures: persistent chemical pollutants in the environment and breast milk. Pediatr Clin North Am. 2007;54(1):81-101.

9. Clapauch R, Meirelles RMR, Julião MASG, Loureiro CKC, Giarodoli PB, Pinheiro SA, et al. Fitoestrogênios: posicionamento do Departamento de Endocrinologia Feminina da SBEM. Arq Bras Endocrinol Metab. 2002;46(6):679-95.

10. Newbold R. Cellular and molecular effects of developmental exposure to diethylstilbestrol: implications for other environmental estrogens. Environ Health Perspect. 1995;103(Suppl 7):S83-7.

11. Stockholm Convention Secretariat, Stockholm Convention on persistent organic pollutants. [Database on the internet], Stockholm 2008. Disponivel em: http://www.pops.int/documents/ convtext/convtext_en.pdf. Acesso em: 29 de março de 2009.

12. Sutek K. [Nobel prize for Paul Hermann Müller in 1948 for discovery of DDT insecticide] Wiad Lek. 1968;21(18):1698. [Article in Polish]

13. Woodwell GM, Wurster CF Jr, Isaacson PA. DDT residues in an east coast estuary: a case of biological concentration of a persistent insecticide. Science. 1967;156(3776): 821-4.

14. Gray LE Jr, Wolf C, Lambright C, Mann P, Price M, Cooper RL, et al. Administration of potentially antiandrogenic pesticides (procymidone, linuron, iprodione, chlozolinate, $\mathrm{p}, \mathrm{p}^{\prime}-\mathrm{DDE}$, and ketoconazole) and toxic substances (dibutyl- and diethylhexyl phthalate, PCB 169 , and ethane dimethane sulphonate) during sexual differentiation produces diverse profiles of reproductive malformations in the male rat. Toxicol Ind Health. 1999;15(1-2):94-118.

15. De Jager $C$, Farias $P$, Barraza-Villarreal A, Avila MH, Ayotte $P$, Dewailly $E$ et al. Reduced seminal parameters associated with environmental DDT exposure and $p, p^{\prime}$-DDE concentrations in men in Chiapas, Mexico: a cross-sectional study. J Androl. 2006;27(1):16-27.

16. Birch JM, Blair V. Increase in childhood carcinomas in Northwest England [Letter]. Lancet. 1988;1:833.

17. Sandrini R, Ribeiro RC, DeLacerda L. Childhood adrenocortical tumors. J Clin Endocrinol Metab. 1997;82(7):2027-31.

18. Figueiredo BC, Sandrini R, Zambetti GP, Pereira RM, Cheng C, Liu W, et al. Penetrance of adrenocortical tumours associated with the germlineTP53 R337H mutation. J Med Genet. 2006;43(1):91-6.

19. Associação de Combate aos Poluentes Orgânicos (ACPO). [Database on the internet] Santos,SP. Fundada em 3 de novembro de 1994. Disponivel em: http://www.acpo.org.br/principal.php Acesso em: 29 de março de 2009.
20. Penteado JCP, Vaz JM. O legado das bifenilas policloradas (PCBs). Quim Nova. 2001;24(3):390-98.

21. Walters DM, Fritz KM, Johnson BR, Lazorchak JM, McCormick FH. Influence of trophic position and spatial location on polychlorinated biphenyl (PCB) bioaccumulation in a stream food web.Environ Sci Technol. 2008;42(7):2316-22.

22. Mazhitova Z, Jensen S, Ritzen M, Zetterstrom R. Chlorinated contaminants, growth and thyroid function in schoolchildren from the Aral Sea region in Kazakhstan. Acta Paediatr. 1998;87:991-5.

23. Sher ES, Xu XM, Adams PM, Craft CM, Stein SA. The effects of thyroid hormone level and action in developing brain: are these targets for the actions of polychlorinated biphenyls and dioxins? Toxicol Ind Health. 1998;14:121-58.

24. Andric SA, Kostic TS, Stojilkovic SS, Kovacevic RZ. Inhibition of rat testicular androgenesis by a polychlorinated biphenyl mixture aroclor 1248. Biol Reprod. 2000;62:1882-8.

25. Wojtowicz AK, Gregoraszczuk EL, Lyche JL, Ropstad E. Time dependent and cell-specific action of polychlorinated biphenyls (PCB 153 and PCB 126) on steroid secretion by porcine theca and granulosa cells in mono- and coculture. J Physiol Pharmacol. 2000;51:555-68.

26. Brandt I. Tissue localization of polychlorinated biphenyls. Chemical structure related to pattern of distribution. Acta Pharmacol Toxicol (Copenh). 1977;40(Suppl 2):1-108.

27. Durham SK, Brouwer A. 3, 4, 3', 4'-Tetrachlorobiphenyl distribution and induced effects in the rat adrenal gland. Localization in the zona fasciculata. Lab Invest. 1990;62:232-9.

28. Denison MS, Whitlock Jr JP. Xenobiotic-inducible transcription of cytochrome P450 genes. J Biol Chem. 1995;270:18175-8.

29. Li LA, Wang PW, Chang LW. Polychlorinated biphenyl 126 stimulates basal and inducible aldosterone biosynthesis of human adrenocortical H295R cells. Toxicol Appl Pharmacol. 2004;195:92-102.

30. Li LA, Wang PW. PCB126 induces differential changes in androgen, cortisol, and aldosterone biosynthesis in human adrenocortical H295R cells. Toxicol Sci. 2005;84:1-11.

31. Lin TC, Chien SC, Hsu PC, Li LA. Mechanistic study of polychlorinated biphenyl 126-induced CYP11B1 and CYP11B2 up-regulation. Endocrinology. 2006;147(3):1536-44.

32. Gustavsson P, Hogstedt C. A cohort study of Swedish capacitor manufacturing workers exposed to polychlorinated biphenyls (PCBs). Am J Ind Med. 1997;32:234-9.

33. Hay A, Tarrel J. Mortality of power workers exposed to phenoxy herbicides and polychlorinated biphenyls in waste transformer oil. Ann NY Acad Sci. 1997;837:138-56.

34. Longnecker MP, Klebanoff MA, Brock JW, Zhou H. Polychlorinated biphenyl serum levels in pregnant subjects with diabetes. Diabetes Care. 2001;24:1099-101.

35. Fierens S, Mairesse H, Heilier JF, De Burbure C, Focant JF, Eppe G, et al. Dioxin/polychlorinated biphenyl body burden, diabetes and endometriosis: findings in a population-based study in Belgium. Biomarkers. 2003;8:529-4.

36. Cao XL, Corriveau J. Migration of bisphenol A from polycarbonate baby and water bottles into water under severe conditions. J Agric Food Chem. 2008;56(15):6378-81.

37. Wetherill YB, Akingbemi BT, Kanno J, McLachlan JA, Nadal A, Sonnenschein $C$, et al. In vitro molecular mechanisms of bisphenol A action. Reprod Toxicol. 2007;24(2):178-98.

38. Bonefeld-Jørgensen EC, Long M, Hofmeister MV, Vinggaard AM. Endocrine-disrupting potential of bisphenol A, bisphenol A dimethacrylate, 4-n-nonylphenol, and 4-n-octylphenol in vitro: new data and a brief review. Environ Health Perspect. 2007;115 (Suppl 1):69-76.

39. Calafat AM, Kuklenyik Z, Reidy JA, Caudill SP, Ekong J, Needham LL. Urinary concentrations of bisphenol A and 4-nonylphe- 
nol in a human reference population. Environ Health Perspect. 2005;113(4):391-5.

40. Lang IA, GallowayTS, Scarlett A, Henley WE, Depledge M, Wallace $R B$, et al. Association of urinary bisphenol A concentration with medical disorders and laboratory abnormalities in adults. JAMA. 2008; 300(11):1303-10.

41. Wajchenberg BL, Nery M, Cunha MR, Silva MER. Adipose tissue at the crossroads in the development of the metabolic syndrome, inflammation and atherosclerosis. Arq Bras Endocrinol Metab. 2009;53(2):145-50.

42. Hugo ER, Brandebourg TD, Woo JG, Loftus J, Alexander JW, BenJonathan $\mathrm{N}$. Bisphenol A at environmentally relevant doses inhibits adiponectin release from human adipose tissue explants and adpocytes. Environ Health Perspect. 2008;116:1642-7.

43. Grün F, Blumberg B. Environmental obesogens: organotins and endocrine disruption via nuclear receptor signaling. Endocrinology. 2006;147(Suppl 6):S50-5.

44. Shathyanarayana S, Karr CJ, Lozano P, Brown E, Calafat AM, Liu F, Swan SH. Baby care products: possible sources of infant phthalates exposure. Pediatrics. 2008;121(2):e260-8.

45. Swan SH, Main KM, Liu F, Stewart SL, Knuse RL, Calafat AM, et al. Decrease in anogenital distance among male infants with prenatal phthalate exposure. Environ Health Perspect. 2005;113:1056-61.

46. Main KM, Mortensen GK, Kaleva MM, Boisen KA, Damgaard IN, Chellakooty M, et al. Human breast milk contamination with phthalates and alterations of endogenous reproductive hormones in infants three months of age. Environ Health Perspect. 2006;114(2):270-6.

47. Lambrot R, Muczysnki V, Lecureuil C, Angenard G, Coffigny H, Pairault $\mathrm{C}$, et al. Phthalates impair germ cell development in the human fetal testis in vitro without change in testosterone production. Environ Health Perspect. 2009;117:32-7.

48. 48. Ross PS, De Swart RL, Reijnders PJ, Van Loveren H, Vos JG, Osterhaus AD. Contaminant-related suppression of delayed-type hypersensitivity and antibody responses in harbor seals fed herring from the Baltic Sea. Environ Health Perspect. 1995;103(2):162-7.

49. Sørmo EG, Larsen HJ, Johansen GM, Skaare JU, Jenssen BM. Immunotoxicity of polychlorinated biphenyls (PCB) in free-ranging gray seal pups with special emphasis on dioxin-like congeners. $J$ Toxicol Environ Health A. 2009;72(3-4):266-76.

50. Bowerman WW, Best DA, Grubb TG, Sikarskie JG, Giesy JP. Assessment of environmental endocrine disruptors in bald eagles of the Great Lakes Chemosphere. 2000;41(10):1569-74.

51. Kannan K, Tao L, Sinclair E, Pastva SD, Jude DJ, Giesy JP. Perfluorinated compounds in aquatic organisms at various trophic levels in a Great Lakes food chain. Arch Environ Contam Toxicol. 2005;48(4):559-66.

52. Strand J, Jorgensen A, Tairova Z. TBT pollution and effects in molluscs at US Virgin Islands Caribean Sea. Environ Int. 2009;35(4):707-11.
53. Semenza JC, Tolbert PE, Rubin CH, Guillette LJ Jr, Jackson RJ. Reproductive toxins and alligator abnormalities at Lake Apopka, Florida. Environ Health Perspect. 1997;105(10):1030-2.

54. Fernández MF, Olmos B, Olea N. Exposure to endocrine disruptors and male urogenital tract malformations (cryptorchidism and hypospadias). Gac Sanit. 2007;21(6):500-14.

55. Queiroz EK, Waissmann W. Occupational exposure and effects on the male reproductive system. Cad Saude Publica. 2006;22(3):485-93.

56. Fortes EM, Malerba MI, Luchini PD, Sugawara EK, Sumodjo L, Ribeiro Neto LM, et al. [High intake of phytoestrogens and precocious thelarche: case report with a possible correlation]. Arq Bras Endocrinol Metab. 2007;51(3):500-3.

57. Buck Louis GM, Gray LE Jr, Marcus M, Ojeda SR, Pescovitz OH, Witchel SF, et al. Environmental factors and puberty timing: expert panel research needs. Pediatrics. 2008;121(Suppl 3):S192-207.

58. Den Hond E, Schoeters G. Endocrine disrupters and human puberty. Int J Androl. 2006;29(1):264-71.

59. Landrigan P, Garg A, Droller DBJ. Assessing the effects of endocrine disruptors in the National Children's Study. Environ Health Perspect. 2003;111(13):1678-82.

60. Newbold RR, Padilla-Banks E, Jefferson WN, Heindel JJ. Effects of endocrine disruptors on obesity. Int J Androl. 2008;31(2):201-8.

61. Vedana EHB, Peres MA, Neves J, Rocha GC, Longo GZ. Prevalência de obesidade e fatores potencialmente causais em adultos em região do sul do Brasil. Arq Bras Endocrinol Metab. 2008;52(7):1156-62.

62. Colborn T, Dumanoski D, Myers JP. Nosso futuro roubado (Our Stolen Future). 10a. Lisboa: Dinalivro; 1999.

63. Martin OV, Lester JN, Voulvoulis N, Boobis AR. Human health and endocrine disruption: a simple multicriteria framework for the qualitative assessment of end point-specific risks in a context of scientific uncertainty. Toxicol Sci. 2007;98(2):332-47. Epub 2007 Jan 25

64. Bovet C, Wortmann A, Eiler S, Granger F, Ruff M, Gerrits B, et al. Estrogen receptor-ligand complexes measured by chip-based nanoelectrospray mass spectrometry: an approach for the screening of endocrine disruptors. Protein Sci. 2007; 16(5):938-46. Epub 2007 Mar 30.

65. Adriaens $P$, Goovaerts $P$, Skerlos $S$. Intelligent infrastructure for sustainable potable water: a roundtable for emerging transnational research and technology development needs. Biotechnol Adv. 2003;22(1-2):119-34.

66. Quental N, Moraes MJ. [Database on the internet] Grupo de estudos ambientais da Escola Superior de Biotecnologia da Universidade Católica Portuguesa. Disponível em: http://www.esb.ucp. pt/gea/myfiles/pops/index.htm. Acesso em: 27 de março de 2009.

67. Austen I. [Database on the internet] Canada takes steps to ban most plastic baby bottles. NY Time. NY. 19 de abril de 2008. Acesso em: 29 de março de 2009. Disponível em: http://www. nytimes.com/2008/04/19/business/worldbusiness/19plastic. html?ref=Americas. 